\title{
NOTAS SOBRE A QUESTÃO DA SINGULARIDADE DA FALA DA CRIANÇA
}

\author{
Glória Maria Monteiro de CARVALHO ${ }^{1}$
}

\begin{abstract}
Resumo: Neste artigo, coloca-se em discussão o caráter singular da fala da criança, no momento de mudança da condição de infans à condição de falante, sendo a singularidade concebida como uma transgressão, uma ruptura de padrões da língua. A fim de atribuir um estatuto teórico à referida concepção, é destacada a noção de anagrama que provoca uma ruptura no significante, conforme instituído por Saussure. Estendendo essa noção à fala infantil, são abordados fragmentos de enunciados produzidos por uma criança em um momento inicial de sua trajetória linguística. A partir de tal abordagem, propõe-se, então, que a escuta da singularidade da fala infantil, pelo investigador, implicaria a escuta de uma transgressão da linearidade do significante da fala do outro/falante.
\end{abstract}

Palavras-chave: Singularidade. Transgressão. Anagrama. Significante. Fala da criança.

\section{Introdução}

Este trabalho consiste numa tentativa de colocar em discussão a singularidade da fala da criança. Fazendo coro com alguns autores, assumo a noção de singularidade como sendo transgressão. Abro aqui um espaço para dar destaque à necessidade de se determinar o sentido em que se usa o termo transgressão. A partir desse destaque, focalizarei a noção de transgressão, no sentido de atribuir-lhe estatuto teórico, a fim de tornar viável a tentativa de colocar em discussão a singularidade da fala da criança.

A primeira pergunta que se colocou foi: em um momento muito inicial da aquisição de linguagem, a fala da criança transgride... o quê? Acreditamos, então, que seria preciso seguir o

\footnotetext{
${ }^{1}$ UNICAP - Universidade Católica de Pernambuco - Programa de Pós-graduação em Ciências da Linguagem. Recife - Pernambuco - Brasil. 52041-040 - gloria.carvalho@pq.cnpq.br 
caminho aberto por essa pergunta para tentarmos atribuir estatuto teórico à transgressão e, portanto, à singularidade.

Baseamo-nos em autores como, por exemplo, Jean Claude Milner (2012), para assumir que se trata de uma transgressão ao significante segundo a concepção de Saussure. Precisamos passar, então, a um confronto com o significante, nessa perspectiva.

\section{Vicissitudes na elaboração saussuriana de signo}

Em relação à concepção de signo elaborada no Curso de Linguística Geral - que, a partir de agora, será referido pelas iniciais CLG -, filiamo-nos a autores, como: Depecker (2012), Arrivé (2008), Túlio De Mauro (1985), que assumem a posição de que as vicissitudes, no percurso da elaboração saussuriana, estariam indicando uma tentativa de excluir, dessa noção, os vestígios de substancialidade que o som lhe imprimia. Essas vicissitudes se tornam visíveis nos manuscritos deixados por Saussure.

Depecker (2012), a partir de uma análise minuciosa do movimento dos dois termos do signo, nos manuscritos, em relação à imagem acústica, afirma ter havido a substituição de som por figura acústica, estando também presentes as expressões: impressão acústica, imagem verbal, imagem auditiva, chegando ao termo significante. A esse respeito, afirma que: "Diante da ambiguidade dos termos usuais, Saussure tenta outras terminologias, para dar corpo àquilo que deseja demonstrar: pelo menos a associação e a reciprocidade entre os constituintes do signo.” (DEPECKER, 2012, p.89). Em 19 de maio de 1911, de acordo com os manuscritos, Saussure propõe os termos significante e significado:

O momento em que Saussure se decide por uma terminologia para designar os constituintes do signo e o todo que eles constituem está datado. [...]. Após ter tratado com seus estudantes, fora das sessões precedentes, a questão do arbitrário, Saussure estabelece essa posição, no início da sessão de 19 de maio, ressaltando 'dois princípios fundamentais relativos ao signo linguístico’. (DEPECKER, 2012, p. 90)

No que diz respeito à substituição de imagem acústica por significante e de conceito por significado, diz Arrivé (2008, p. 99) que "as duas faces perdem tudo o que lhes restava de característica substancial.”.

Túlio De Mauro, numa nota da edição crítica - por ele preparada - do CLG (SAUSSURE, 1985), chama a atenção para a concepção saussuriana de arbitrariedade do signo, após a introdução dos termos significante e significado: "O laço unindo significante e 
significado é radicalmente arbitrário" (SAUSSURE, 1985, p. 442, notas do editor, tradução minha). Destaca aquele autor que os editores do CLG suprimiram, de forma equivocada, o advérbio radicalmente, mostrando, a esse respeito, o quão difícil é imaginar que esse advérbio tenha sido utilizado como pleonasmo geral de reforço:

É mais legítimo supor que ele (o advérbio) tem aqui seu pleno sentido: o laço é arbitrário radicitus, em seus próprios fundamentos, na medida em que ele liga duas entidades aparentemente produzidas graças a um corte arbitrário na substância acústica e na substância significativa. (SAUSSURE, 1985, p. 442, notas do editor, tradução minha)

Queremos realçar, portanto, que a presença desses termos, ou a substituição de um termo por outro, não seria banal ou casual, isto é, não significaria apenas uma substituição terminológica, mas, ao contrário, teria consequências e implicaria uma complexidade.

Destacamos a substituição de som por figura acústica (vocal) e, aqui, estamos nos baseando nos Escritos (Escritos de linguística geral, 2004). Saussure refere-se ao domínio fisiológico-acústico (não linguístico) da figura vocal que se impõe como igual a si mesma, independentemente de toda língua.

Diz esse autor:

Uma figura vocal se torna uma forma a partir do instante em que é introduzida no jogo dos signos que se chama língua, da mesma maneira que um pedaço de pano jogado no fundo de um navio se torna um sinal, no instante em que é içado entre outros signos içados no mesmo momento e que contribuem para uma significação. (SAUSSURE, 2004, p. 38)

Nesse sentido, segundo Saussure, a figura vocal não existe para o linguista nem para o falante. Afirma, então:

As figuras vocais que servem de signo não existem mais na língua instantânea. Elas existem, então, para o físico, para o fisiologista, não para o linguista e nem para o sujeito falante. Assim como não há significação fora do signo $a$, assim também não há signo fora da significação. (SAUSSURE, 2004, p. 67)

Mais adiante, coloca: “Toda coisa material é já, para nós, signo: ou seja, a impressão que associamos a outras, mas a coisa material parece indispensável.” (SAUSSURE, 2004, p. $103)$.

Com fundamento em Milner (2012), podemos dizer que o som, ou qualquer resto sonoro, precisaria ser excluído em favor do diferencial do significante, na tentativa do linguista de 
constituir a língua como um sistema. (CARVALHO; VILAR DE MELO, 2013). Para Milner, em $O$ amor da língua, aquilo que, nessa tentativa, fora excluído - por meio de uma operação que ele nomeia de forclusão, de acordo com a proposta psicanalítica - teria retornado nos anagramas saussurianos. Nesse sentido, diz o autor, "o anagrama, a bem dizer, renega o signo." (MILNER, 2012, p. 86)

\section{Os anagramas de Ferdinand de Saussure}

Com fundamento no que foi colocado no final do item anterior, podemos dizer que os anagramas constituem um domínio especial para se abordar a transgressão. Segundo Jakobson (1990), a transgressão do significante pelo anagrama consiste na transposição da linearidade do significante. A respeito do anagrama poético, diz que:

O anagrama poético transpõe as duas 'leis fundamentais da palavra humana' proclamadas por Saussure, a do vínculo codificado entre o significante e seu significado, e a da linearidade dos significantes. Os meios da linguagem poética fazem-nos mesmo sair 'fora da ordem linear' ou, como diz Starobinsky, saímos do tempo da 'consecutividade' própria da linguagem habitual (JAKOBSON, 1990, p. 12)

Convém lembrar que a linearidade, concebida como consecutividade temporal, consiste, para Saussure (1989), na lei fundamental da palavra humana: os componentes fônicos da palavra se seguem temporalmente. Ao conceituar as relações sintagmáticas, afirma:

De um lado, no discurso, os termos estabelecem entre si, em virtude de seu encadeamento, relações baseadas no caráter linear da língua, que exclui a possibilidade de pronunciar dois elementos ao mesmo tempo [...] O sintagma se compõe sempre de duas ou mais unidades consecutivas [...]. (SAUSSURE, 1989, p. 142)

Vale ainda notar, com Milner (2012), que, embora o anagrama, ao que parece, tenha, em versos saturninos, seu lugar de especial visibilidade, ele seria inerente à língua, estando presente nos versos de todos os tipos, de todas as épocas e, mais ainda, em qualquer texto. Destaca esse autor:

Tudo repousa, conforme as articulações de Saussure, no fato de que uma série de fonemas sempre pode ecoar uma outra e, por isso, significá-la criptograficamente. Ora, nem é preciso dizer que é assim necessariamente. Uma observação levemente acurada já é o bastante: abra ao acaso o texto que 
for - Meillet fez essa experiência - e os anagramas irromperão, impossíveis de sufocar. (MILNER, 2012, p. 88)

Abrimos aqui um parêntese para rapidamente relembrar que fragmentos manuscritos da proposta de Saussure sobre os anagramas por ele analisados, sobretudo, em antigos poemas, foram selecionados e comentados por Jean Starobinski. Lanço mão, portanto, da publicação desse autor: "As palavras sob as palavras de 1974"2. Nesse texto, o anagrama, na perspectiva saussuriana, consiste na operação pela qual os fonemas de determinada palavra se redistribuem no verso, como nos exemplos (extraídos de Starobinski, 1974, p. 105), em que as palavras-tema Falerni, Ulixes e Circe redistribuem seus fonemas em facundi calices hausere-alterni, Urbium simul Undique pepulit lux umbras .. resides e Cicuresque, respectivamente, conforme se seguem:

... / facundi calices hausere - alterni /

FA AL ER ALERNI

(2) / Urbium simul / Undique pepulit lux umbras .. resides /

U-----------UL U-----------ULI---X--------S-----S--ES

Cicuresque /
CI - R- CE

Vale também mostrar um exemplo de anagrama, num verso mais atual, extraído do poema Le vieux saltimbanque ( $O$ velho saltimbanco) de Baudelaire (citado por Starobinski, 1974, p. 12):

(4) / Je sentis ma gorge serrée par la main terrible de l'histerie $/^{3}$.

HY------------S--------------------TERIE

Em relação a esse último exemplo, para Starobinski (1974, p. 158), tudo acontece como se a palavra final fornecesse, de modo antecipado, "a trama condutora das palavras antecedentes"; a histeria surge, assim, com toda clareza, logo após ter sido anunciada de

\footnotetext{
2 Tradução da publicação de Starobinski: Les mots sous des mots, de 1971.

${ }^{3} \mathrm{Eu}$ senti minha garganta fechada pela mão terrível da histeria.
} 
maneira difusa, ao mesmo tempo, por seus efeitos no nível do significado e por seus fenômenos constitutivos no nível do significante.

Essa escuta das palavras-tema (exemplificadas) afronta o princípio da linearidade do significante, na medida em que afronta o princípio de que os elementos que formam uma palavra se seguem. Por exemplo, de forma mais visível, em Cicuresque, os elementos que formam a palavra Circe não se seguem, quer dizer, seus componentes se distanciam, o que se pode ver, nos vários exemplos dados, chamando a atenção para o fato de que se trata de um distanciamento do ponto de vista fônico e não de um distanciamento espacial de seus componentes, na escrita.

No entanto, Saussure usa o termo anafonia para designar "o anagrama incompleto, que apenas imita algumas sílabas de uma dada palavra, sem se submeter a reproduzi-la inteiramente." (STAROBINSKI, 1974, p. 27).

Segundo Starobinski (1974), Saussure enfrenta, contudo, alguns problemas particulares, no que diz respeito à sílaba, ou melhor, ao dífono. Assim, um dífono submetido a uma anafonia pode ter seus dois elementos (inseparáveis) distanciados um do outro.

Para Saussure, "O princípio do dífono quer dizer que se representam as sílabas na CONSECUTIVIDADE de seus elementos." (STAROBINSKI, 1974, p. 34). Diz o mestre genebrino que a distribuição de $T A E$ em $t a+t e$ convida o leitor a fazer uma média das impressões acústicas, fora do tempo, isto é, fora da ordem que os elementos têm no tempo, “como eu poderia fazê-lo com duas cores simultâneas." (STAROBINSKI, 1974, p. 35)

Sobre a palavra-tema, diz Milner (2012, p. 87):

- o anagrama não é diferencial: cada um dos anagramas repousa sobre um determinado nome cujos fonemas ele redistribui. Mas está claro que esse nome (próprio ou comum), ainda que seja uma unidade linguística, não é tratado a partir daquilo que tem de diferencial: ele tem uma identidade própria, um Si que não é extraído da rede de oposições na qual a linguística iria apreendê-lo.

Nesse sentido, apelamos para autores como Vivès (2012) e Didier Weill (1999) que se referem ao som como a dimensão imaginária (do real) da voz, na perspectiva lacaniana, isto é, aquilo que, da voz, é possível de ser representado. Assim, nesse nível, a dimensão imaginária, dimensão do si mesmo, se de um lado consiste na base, no suporte da representação, de outro lado, toca no real da voz, daí, talvez, a sua força transgressora, de acordo com essa perspectiva. Sobre a sonoridade da voz materna, afirma Didier Weill (1999, p. 154): 
Este infans teria, assim, que encarar o fato de que a linguagem lhe seria transmitida como habitada por essa contradição interna: por um lado, é-lhe transmitida uma lei simbólica fundada na integração das escansões linguageiras, própria para transmitir o sentido simbólico do código; por outro lado, é-lhe transmitida ao mesmo tempo uma subversão desta lei: a pura continuidade sonora produzida pela voz dessa diva que é a mãe tende, com efeito, a abolir a descontinuidade que transmite a inteligibilidade do sentido.

Assim, ao indicar a dupla face - continuidade e descontinuidade - da sonata materna, o autor citado dá especial realce ao caráter transgressor da continuidade sonora produzida pela voz da mãe.

\section{Os anagramas e a singularidade da fala da criança}

Fechando o parêntese, voltemos à proposta milneriana segundo a qual o som (com seu caráter de "mesmo") que foi excluído/forcluído em favor do diferencial do significante, retorna no anagrama, colocando em questão esse diferencial. Podemos voltar então à proposta de que o som transgride o significante, na tentativa de atribuir estatuto teórico à noção de transgressão e, portanto, à noção de singularidade. Como se trata de singularidade da fala da criança, ou melhor, trata-se de transgressão da linearidade do significante da fala do outro provocada pela dimensão sonora da fala da criança, convoquemos Pommier (2004) segundo quem é preciso que a criança esqueça/recalque o som para que se torne falante. Nesse sentido afirma:

O diferencial esquece o som, recalca o som do objeto quando ele se torna uma letra que participa da formação de um significante. Se digo 'lobo', vocês pensarão no animal e esquecerão a música do som ' $l o$ ' com a qual podemos cantarolar. $\mathrm{O}$ diferencial dos objetos pulsionais tornados letras engole a música. (POMMIER, 2004, p. 124)

Convém destacar que, nessa perspectiva, o som recalcado retorna como matéria-prima de formações do inconsciente, como nos chistes, nos atos falhos.

Vale notar também que a operação de apagamento do som por Saussure consiste, segundo Milner, na forclusão, enquanto que Pommier se refere ao esquecimento, ao recalque como operação de apagamento que ocorre na criança para se tornar falante.

Para Milner (2012, p. 92):

Quanto àquilo que dá azo à função de excesso, que seja a homofonia e não outra coisa, isso decorre diretamente do conceito de signo. Através desse último, a língua vinha sendo pensada como calculável em razão do que ela 
tem de diferencial - o forcluído não podia retornar, então, a não ser na forma daquilo que desfaz o diferencial: o eco contingente.

É importante lembrar que, do ponto de vista psicanalítico, na forclusão, “o significante que foi rejeitado da ordem simbólica reaparece no real" (CHEMAMA, 1995, p. 80). Desse modo, o que foi rejeitado não pode mais retornar ao lugar de onde havia sido excluído. Por sua vez, o recalque consiste, em sua forma geral, no "processo de afastamento das pulsões às quais é rejeitado o acesso à consciência.” (CHEMAMA, 1995, p. 185). Nessa perspectiva, a forclusão se distingue do recalque, "pois o recalcado retorna a seu lugar de origem, o simbólico, no qual havia sido primitivamente admitido." (CHEMAMA, 1995, p. 80) ${ }^{4}$.

\section{Um exemplo de transgressão provocada pela produção verbal infantil}

Considerando o caráter transgressivo da relação entre som e significante, mas, sobretudo, destacando as diferenças na realização dessa transgressão pelos anagramas e pela fala da criança, daremos, neste momento, um exemplo de nossa escuta da singularidade de uma produção verbal infantil.

(5) A título de ilustração, citamos o caso de uma criança que, aos 15 meses, repete constantemente o segmento "Ca" o qual aparece nas manifestações verbais: "Ca papá", "Ca vovô", "Ca vovó", "Ca titi", provavelmente como restos (sonoros) de cenas anteriores em que os pais mostram os carros, dizendo: "carro de papai", "carro de vovô" etc., segundo a noção de espelhamento de Cláudia Lemos, num momento muito inicial da trajetória linguística da criança. Numa determinada ocasião, na casa dos avós, o avô mostra à criança um quadro pendurado na parede, pronunciando pausadamente: "quadro". A criança repete "Ca" e, imediatamente depois diz: "Ca vovó", "Ca papá", aproximando, com base numa semelhança sonora, quadro e carro.

Num outro momento, pegando o colar da avó, que estava sobre uma mesa, a criança diz: "Ca vovó", produzindo imediatamente depois: "Ca vovô". A avó refuta, dizendo: "homem não usa colar; quem usa é mulher". Simultaneamente à fala da avó, o menino verbaliza: "ca papá”, “ca titi”.

\footnotetext{
${ }^{4}$ Não nos cabe, neste trabalho, levar adiante a concepção psicanalítica desses dois processos - o recalque e a forclusão -, mas, apenas, indicar que são diferentes, sobretudo em relação à maneira como retornam.
} 
Com fundamento em Lemos (2002), podemos dizer que o segmento "quadro" convocou "carro", na escuta da criança, em virtude de uma semelhança sonora. No segundo momento, o grupo sonoro "colar" evocou, na verbalização da criança, o segmento "ca" que se associa à "ca" de "carro". Não podemos dizer que se trata apenas de associações sonoras, ou seja, não poderíamos assegurar que se trata do "puro" som. Provavelmente, outros tipos de associações se fazem presentes nos jogos sonoros da criança, interferindo nesses jogos. No entanto, sobre essa interferência, nada podemos dizer com segurança, restando, portanto, uma interrogação. Em relação ao exemplo dado, poderíamos supor que a escuta, pela criança, de "ca" em "colar", poderia ter sofrido a influência da circunstância de que o uso do colar pela avó teria sido comumente percebido, pela criança, quando ambas estavam no carro, durante algum passeio em família. Assim, mesmo admitindo a ocorrência de outros tipos de associações, assumimos que o som seria dominante, nas manifestações verbais da criança, num momento inicial. Dizendo melhor, outros tipos de associações, que não se poderiam determinar com segurança, estariam submetidos à dominância do som, nesse momento.

Nesse sentido, Porge concebe um estádio de eco que seria estruturante do sujeito, isto é, seria constitutivo do falante, propondo que:

O estádio de eco estaria ligado a este momento de passagem do grito ao apelo e à palavra com a voz como objeto resto, um momento constitutivo da distinção exterior-interior correlativo de toda identificação e, portanto correlativo também de um retorno (ou giro?) onde há um exterior do interior. A ecolalia do autista seria a fixação a este momento que é também estrutural. (PORGE, 2012, p. 90, tradução minha)

Assim, na proposta psicanalítica, com fundamento em autores como: Didier Weill (1999), Vivès (2012) e Porge (2012), para se tornar falante, a criança precisa perder/esquecer/recalcar a voz e conservar o sentido, o que, entretanto, somente ocorre se o objeto voz se mantém, no sujeito, como inscrição significante.

A esse respeito, coloca Vivès (2012, p. 13):

O apagamento da voz em face do que é dito pode ser facilmente observado quando alguém toma a palavra. A princípio, podemos ser capturados pelas características da Voz (a entonação, por exemplo), mas isso rapidamente desaparece quando começamos a prestar atenção no que é dito. A fala vela a voz.

Por sua vez, esse autor realça que a música (por exemplo, a ópera) tem o poder de tornar a voz perceptível em busca de um gozo estético. 
Destacando, a seguir, o efeito de transgressão provocado na escuta do investigador para a fala da criança, indicamos que o "ca" (fragmento do conjunto sonoro: "carro") se distribui em "quadro" e em "colar", transgredindo a linearidade do significante, na medida em que o "ca" [ka] tem seus componentes fônicos - [k] e [a] separados, temporalmente, em "quadro" e "colar", quebrando assim a regra da consecutividade temporal.

Convém realçar, entretanto, que, embora na escuta do investigador, os componentes fônicos do [ka] (de "carro") apareçam, temporalmente, separados em [kwa] de "quadro", essa separação temporal merece uma nota. Assim, tanto em "carro", quanto em "quadro" - os dois segmentos (c [k] e a [a] que formam ca [ka]) encontram-se em uma mesma sílaba e obedecem ao mesmo ritmo, desde que, em ambos os casos, trata-se da sílaba acentuada, no dissílabo paroxítono. Acrescente-se, ainda, o fato de que em [kwa] existem, não duas vogais, mas uma vogal [a] e uma semivogal [w].

Por sua vez, no que diz respeito aos conjuntos fônicos "carro" e "colar", tanto os segmentos (c [k] e a [a] que formam ca [ka]) encontram-se em sílabas diferentes, como se diferenciam do ponto de vista rítmico: "carro" é dissílabo paroxítono e "colar" é dissílabo oxítono. Assim, esse caso dá especial visibilidade à circunstância de que os elementos fônicos de ca [ka], ao se distribuírem em "colar", quebram a consecutividade temporal, uma vez que se encontram separados por dois segmentos fônicos ([o] e [1]).

\section{Algumas palavras finais}

Considerando o exemplo apresentado, parece-nos importante realçar que se trata da relação entre som e significante na escuta do investigador, ou melhor, trata-se, nessa escuta, de um efeito de transgressão à linearidade do significante, efeito esse produzido pela fala da criança. Repetimos que se trata da escuta do investigador para essa singularidade ou, ainda dizendo com outros termos, trata-se do efeito produzido, no investigador, pela relação transgressiva entre som e significante, ao escutar a fala da criança. Isso justifica o fato de termos lançado mão dos anagramas saussurianos, na tentativa de atribuir estatuto teórico à transgressão e, portanto, à singularidade, procurando também tirar consequências dessa tentativa; ao mesmo tempo, aponta também para a necessidade de destacar as várias diferenças na escuta dessa transgressão, pelo linguista, em diversos poemas, e pelo investigador, na fala da criança, especificamente num momento em que essa fala é constituída por fragmentos da fala do outro (a mãe), segundo a concepção de espelhamento adotada. Para ficarmos atentas a essas diferenças, indicamos que, segundo Starobinski (1974, p. 74): 
[...] a palavra-tema latente difere do verso manifesto somente pelo seu estreitamento. Ela é uma palavra como as palavras do verso desenvolvido: [...] não é nem de essência superior nem de uma natureza mais humilde. Ela oferece sua substância a uma invenção interpretativa que a faz sobreviver num eco prolongado.

Assim, nos anagramas, Saussure escuta a palavra-tema, ou os fragmentos da palavratema, através dos significantes manifestos, nos versos.

Segundo Starobinski (1974, p. 33), trata-se de "juntar as sílabas diretrizes, como Isis reunia o corpo despedaçado de Osiris". Na investigação da aquisição de linguagem, o investigador escuta a "palavra-tema" manifesta na fala da criança, isto é, escuta o fragmento (ca) produzido pela criança; melhor dizendo, ele escuta esse fragmento (ca) como se fosse a "palavra-tema" cujos componentes fônicos se distribuem no significante "colar", por exemplo, que é um significante da fala do outro/falante, incluindo-se aí o próprio investigador.

Para finalizar, assumimos que, no momento em que o espelhamento é dominante, a escuta da singularidade da fala da criança, pelo investigador, possuiria dupla face, na medida em que implicaria:

- Uma escuta da transgressão que a fala fragmentada da criança provoca na linearidade do significante da fala do outro.

- Uma escuta da transgressão que a fala fragmentada da criança provoca no conceito de significante assumido pelo investigador, o que, no nosso caso, quer dizer uma transgressão do significante, em sua linearidade, em sua consecutividade temporal.

CARVALHO, Glória Maria Monteiro de. Notes on children's speech singularity. Revista do GEL, São Paulo, v. 13, n. 2, p. 79-90, 2016.

\begin{abstract}
In this article, the singular character of the child's speech is put into question, at the moment the child changes from infans condition to become a speaker, conceiving such singularity as a transgression, a break in the language patterns. In order to assign a theoretical status to that conception, this article highlights the notion of anagram, which causes a break in the signifier, as established by Saussure. Extending this concept to the child's speech, we approach utterance fragments produced by a child at an early point in its linguistic trajectory. From this approach, it is proposed that the listening to the singularity of the child's speech, by the investigator, would imply listening to a signifier linearity transgression in the speech of the other / speaker.
\end{abstract}

Keywords: Singularity. Transgression. Anagram. Signifier. Child's speech. 


\section{Referências}

ARRIVÉ, M. Qu'en est-il du signe chez Ferdinand de Saussure?, Journal français de Psychiatrie, Paris, 29, p. 39-41, 2008.

CARVALHO, G. M. M. Espelhamento e diálogo: o lugar ocupado pela homofonia em aquisição de linguagem. Trabalho apresentado no IX Encontro Nacional de Aquisição da Linguagem - ENAL, UFPB, João Pessoa, Paraíba, out. 2013.

CARVAlHO, G. M. M.; VILAR DE MELO, M. de F. Pontos polêmicos no conceito saussuriano de signo. Trabalho apresentado na II Jornada de Estudos Saussurianos, UNICAMP, Campinas, São Paulo, out. 2013.

CHEMAMA, R. Dicionário de Psicanálise. Porto Alegre: Artes Médicas, 1995.

DEPECKER, L. Compreender Saussure a partir dos manuscritos. São Paulo: Editora Cultrix, 2012.

DIDIER WEIL, A. Invocações: Dionísio, Moisés, São Paulo e Freud. Rio de Janeiro: Companhia de Freud, 1999.

JAKOBSON. R. Poética em ação. São Paulo: Editora Perspectiva/Editora da Universidade de São Paulo, 1990.

LEMOS, C. T. G. de. Das vicissitudes da fala da criança e de sua investigação. Cadernos de Estudos Lingüísticos, 42, p. 41-69, 2002.

MILNER, J.-C. O amor da língua. Campinas: Editora da UNICAMP, 2012.

POMMIER, G. Da passagem literal do objeto ao moedor do significante. MELMAN, C. et al. (Orgs.). O significante, a letra e o objeto. Rio de Janeiro: Companhia de Freud, 2004. p. 119126.

PORGE, É. Voix de l'ècho. Toulouse: Éditions Érès, 2012.

SAUSSURE, F. de. Cours de linguistique générale. Edição crítica preparada por T. de Mauro. Paris : Payot, 1985.

Curso de linguística Geral. São Paulo: Editora Cultrix, 1989.

Escritos de linguística geral. Organizados e editados por S. Bouquet e R. Engler. São Paulo: Cultrix, 2004.

STAROBINSKI, J. As palavras sob as palavras: os anagramas de Ferdinand de Saussure. São Paulo: Editora Perspectiva, 1974.

VIVÈS, J.-M. A voz na clínica psicanalítica. Rio de Janeiro: Contra Capa/Corpo Freudiano, 2012.

Submetido em 26/02/2016

Aceito em 19/05/2016. 